\title{
A Study of Lipid Profile and Lipid Peroxidation in Chronic Kidney Disease with Special Reference to Hemodialysis
}

D.S.S.K.Raju', D.L.Lalitha' ${ }^{1}$ and P. Kiranmayi ${ }^{2}$

${ }^{1}$ Department of Biochemistry, MIMS, Nellimarla, India

${ }^{2}$ Department of Biochemistry, Institute of Science, GITAM University, Visakhapatnam, India

\begin{abstract}
Chronic Kidney Disease (CKD) exhibits dyslipidemia and oxidative stress which are well known traditional risk factors for vascular complications. Therefore this study was undertaken to assess the lipid profile and oxidative stress in CKD patients. The study comprised of 95 patients with evidence of CKD. These cases were further divided into 2 groups i.e. non dialysis and hemodialysis groups. There is a significant increase of serum triglycerides and Very Low Density Lipoprotein (VLDL) with a decrease in serum High Density Lipoprotein-Cholesterol (HDL-C) in both non dialysis and hemodialysis groups of CKD patients when compared with control. But there is no alteration in serum total cholesterol and Low Density Lipoprotein Cholesterol (LDL-C) in both groups. Serum Malondialdehyde (MDA) was significantly raised and serum Superoxide Dismutase (SOD) was significantly lowered in CKD patients both in non dialysis and hemodialysis groups when compared with control. The same changes in respect of serum Malondialdehyde (MDA) and Superoxide dismutase (SOD) were also noted in hemodialysis group when compared with non dialysis patients. In hemodialysis patients, the alteration was further aggravated after hemodialysis and these changes were found to be significant when compared with those patients before hemodialysis. All these factors are suggestive of abnormal lipid profile and enhanced lipid peroxidation with decreased antioxidant status. This study would be beneficial for patients with CKD especially those under hemodialysis for instituting antilipidemic drugs and antioxidant therapy which will improve the quality of their lives.
\end{abstract}

Keywords: Chronic kidney disease; Hemodialysis; Dyslipidemia; Lipid peroxidation; Malondialdehyde; Superoxide dismutase

\section{Introduction}

Chronic Kidney Disease (CKD) is becoming a world wide health problem due to increasing incidence and prevalence, high cost, and poor outcomes [1]. It is a pathophysiological process with multiple etiologies resulting in the inexorable attrition of functional nephrons and frequently leading to End Stage Renal Disease (ESRD) necessitating Hemodialysis as a mandatory therapeutic measure. The Kidney Disease Outcomes Quality Initiative defines chronic kidney disease as either kidney damage or a decreased kidney Glomerular Filtration Rate (GFR) of less than $60 \mathrm{ml} / \mathrm{min} / 1.73 \mathrm{~m}^{2}$ for 3 or more months [2].

The Chronic Kidney Disease (CKD) is characterized by specific metabolic abnormalities of plasma lipids both qualitatively and quantitatively [3]. Most common lipid abnormalities encountered are increased serum triglycerides and decreased serum HDLcholesterol with small alteration of other lipoprotein fraction in serum and in dialysis patients there is more of a dyslipidemia rather than hyperlipidemia [4]. This may be a significant risk factor for vascular complications leading to increased morbidity and mortality in CKD patients.

Reactive Oxygen Species (ROS) are produced at constitutive levels in nonphagocytic cells (e.g., glomerular cells and tubular epithelial cells) for preservation of routine cellular physiology. However, derangements in their production can lead to loss of redox homeostasis and oxidative stress and contributes to proinflammatory and profibrotic pathways in the kidney [5]. Formation of ROS is evident in many areas of the kidney, predominantly in the renal cortices, whereas the medulla can be susceptible to hypoxia and less ROS production under physiologic conditions [6,7].

Chronic Kidney Disease (CKD) is a pro-oxidant state and the degree of intracellular and extracellular oxidative stress is related to the severity of renal failure [8]. The oxidative stress depends on the excess production free radical coupled with low concentration of antioxidants. This also has been observed that free radical induced lipid peroxidative tissue damage has played a significant role in the pathogenesis of various renal diseases. Lipid peroxidation is assayed indirectly by production of secondary products like a water soluble three carbon; low molecular weight reactive aldehyde malondialdehyde (MDA) and assessment of antioxidant status can be measured by estimating Serum Superoxide Dismutase (SOD).

Therefore, an attempt has been made in this study to assess the effect of (i) lipid profile and (ii) oxidative stress as evidenced by serum MDA and SOD activity with emphasis on patients under hemodialysis treatment.

\section{Materials and Methods}

The study comprised of a total of 95 patients with evidence of CKD. The patients were admitted into Nephrology unit of MIMS hospital, Nellimarla. The CKD cases were further divided into 2 groups i.e. a non dialysis group (stages I-IV) numbered 50 patients and ESRD group (stage $\mathrm{V}$ ) who were under hemodialysis comprised of 45 patients. They were included in the study on the basis of clinical signs and symptoms of kidney disease along with an elevated blood urea and serum creatinine

*Corresponding author: P. Kiranmayi, Department of Biochemistry, Institute of Science, GITAM University, Visakhapatnam-530076, India, Tel: 0891-2840464: E-mail: kiranmayi.patnala@gmail.com

Received March 18, 2013; Accepted April 17, 2013; Published May 03, 2013

Citation: Raju DSSK, Lalitha DL, Kiranmayi P (2013) A Study of Lipid Profile and Lipid Peroxidation in Chronic Kidney Disease with Special Reference to Hemodialysis. J Clinic Res Bioeth 4: 143. doi:10.4172/2155-9627.1000143

Copyright: (c) 2013 Raju DSSK, et al. This is an open-access article distributed under the terms of the Creative Commons Attribution License, which permits unrestricted use, distribution, and reproduction in any medium, provided the original author and source are credited. 
level and a lowered eGFR. Patients with eGFR values of less than $15 \mathrm{ml} /$ min were included under stage $\mathrm{V}$ (ESRD) and rest of the others whose eGFR ranged from $90 \mathrm{ml} / \mathrm{min}$ to $15 \mathrm{ml} / \mathrm{min}$ were grouped under stages I to IV. The ESRD patients were under hemodialysis in nephrology unit 3 to 4 hours per day, 2-3 times in a week for the last 6 months to 18 months, but non dialysis patients were under conservatively medical therapy.

The control group comprised of 50, age and sex matched healthy subjects who were free of features of kidney disease and having a normal blood urea and serum creatinine level. Individual suffering from diseases likely to modify their lipid profile as well as their oxidative and antioxidative status, were excluded from the study. Likewise persons with history of drugs which are likely to modify the lipid profile, oxidative and antioxidative status were also excluded.

Informed consent was taken from the patients and subjects who participated in the present study. Ethical committee approval has also been obtained.

In all these groups blood urea, serum creatinine, serum lipid profile, serum MDA and SOD concentrations were estimated. The blood urea was estimated by GLDH-Urease method [9]. Serum creatinine was estimated by Jaffes method [10]. The serum total cholesterol and High Density Lipoprotein Cholesterol (HDL-C) were analyzed using cholesterol oxidase method [11,12], triglyceride assessment was carried out by glycerol kinase method [13], while Low Density Lipoprotein Cholesterol (LDL-C) was calculated by using Frieldwald formula [14]. Similarly serum SOD activity was estimated by Kakkar et al method [15] and serum MDA level was estimated by Thiobarbituric acid method [16] method. The estimated Glomerular Filtration Rate (eGFR) was computed by Mayo Clinic Quadratic Equation (MCQE) as this formula estimates more appropriately the GFR in control and cases [17]

Statistical data: All the data are expressed in Mean and Standard deviation. For the statistical significance, $\mathrm{Z}$ test was performed using SPSS software.

\section{Results and Discussion}

Blood urea and serum creatinine registers an increase in their levels in patients with CKD when compared to those of controls $(\mathrm{p}<0.001$, Table 1$)$. The reason attributed to raised blood urea and serum creatinine in patients with CKD is the declining of glomerular filtration. CKD produces characteristic effects on major lipoprotein fractions [18]. Hypertriglyceridemia is one of the most common lipid abnormalities in patients with CKD [19]. In the present study the mean serum triglyceride was significantly elevated in both non dialysis and hemodialysis groups of CKD patients when compared with control $(\mathrm{p}<0.001$; Table 2). This observation is in agreement with Basha et al. [20].

The accumulation of triglycerides leading to triglyceridemia in CKD is the consequence of both a high production and a low catabolism of triglycerides. But the predominant mechanism which is attributed for triglyceridemia in CKD is decreased catabolism of triglycerides [21]. Various factors contribute to this metabolic aberration in CKD, which includes:

a. Diminished lipoprotein lipase (LPL) activity as a consequence of the down regulation of the enzyme gene [22].

b. A disproportionate increase in plasma apolipoprotein C-III which is a possible cause of lipoprotein lipase inactivation in uremia [23].

c. In hemodialysis patients in addition to the above factors, the repeated use of low molecular heparins may also contribute to lipoprotein lipase depletion [24].

d. The presence of inhibitors of lipase in CKD patients [25].

All these factors which lead to a qualitative or quantitative decrease in LPL activity in plasma result in a decreased catabolism of triglycerides in chylomicrons and VLDL.

CKD is usually associated with secondary hyperparathyroidism. The secondary hyperparathyroidism leads to the impaired catabolism of triglyceride-rich lipoproteins, which provide an additional mechanism for raised plasma triglyceride concentrations in CKD [26].

The other alternative mechanism for hypertriglyceridemia in CKD is the increased production of triglycerides. This mechanism involves

\begin{tabular}{|l|l|l|l|}
\hline & Control $(\mathbf{n = 5 0})$ & CKD Non dialysis patients $(\mathbf{n = 5 0 )}$ & CKD Hemodialysis patients $(\mathbf{n = 4 5 )}$ \\
\hline Age $($ mean \pm SD) years & $40.94 \pm 10.02$ & $45.9 \pm 10.50$ & $45.24 \pm 11.03$ \\
\hline $\begin{array}{l}\text { Sex }(\text { males\%) } \\
\text { females\%) }\end{array}$ & 60 & 58 & 54 \\
\hline Blood urea $(\mathrm{mg} / \mathrm{dl})$ & 40 & 42 & 46 \\
\hline Serum Creatinine $(\mathrm{mg} / \mathrm{dl})$ & $27.12 \pm 7.31$ & $90.46 \pm 28.14^{\star *}$ & $125.44 \pm 28.13^{\star *}$ \\
\hline
\end{tabular}

Serum Creatinine $(\mathrm{mg} / \mathrm{dl})$

${ }^{* *} p<0.001$

The diagnostic criteria for CKD like blood urea and serum creatinine were significantly higher $(p<0.001)$ in CKD patients in both non dialysis and hemodialysis groups when compared to control

Table 1: Demographic features and diagnostic parameters in controls and CKD Patients.

\begin{tabular}{|c|c|c|c|}
\hline Parameter & Control $(n=50)$ & CKD Non dialysis group $(n=50)$ & CKD Hemodialysis group $(n=45)$ \\
\hline Serum Triglycerides (mg/dl) & $113.82 \pm 17.83$ & $209.80 \pm 32.43^{* *}$ & $195.42 \pm 19.13^{* *}$ \\
\hline Serum Total cholesterol (mg/dl) & $177.26 \pm 14.17$ & $182.46 \pm 22.12$ & $173.71 \pm 22.80$ \\
\hline Serum HDL-C (mg/dl) & $45.54 \pm 4.26$ & $35.28 \pm 5.67^{* *}$ & $29.97 \pm 3.93^{* *}$ \\
\hline Serum LDL-C (mg/dl) & $108.95 \pm 13.65$ & $105.22 \pm 26.15$ & $104.64 \pm 22.96$ \\
\hline Serum VLDL (mg/dl) & $22.76 \pm 3.56$ & $41.96 \pm 6.48^{* *}$ & $39.08 \pm 3.82^{* *}$ \\
\hline
\end{tabular}

** $p<0.001$

The mean serum triglycerides and VLDL are increased in CKD in both non dialysis and hemodialysis patients when compared to control. The increase is statistically significant $(p<0.001)$. The mean serum HDL cholesterol is significantly decreased in non dialysis and hemodialysis patients in $C K D$ when compared to control ( $<<0.001)$. The mean serum total cholesterol and LDL cholesterol is not significantly altered when compared with control 
impaired carbohydrate tolerance and enhanced hepatic VLDL synthesis [27]. However its contribution to triglyceridemia is minimal in CKD.

In the present study, serum cholesterol is not altered in CKD patients in both non dialysis and hemodialysis groups when compared with control group. Tsumura et al. [28] observed hypercholesterolemia in their study of patients with CKD. Hypercholesterolemia in their cases was attributed to heavy proteinuria. The mechanism attributed to hypercholesterolemia due to heavy proteinuria in CKD involves altered gene expression of HMG-COA reductase, 7 alpha hydroxylase and hepatic LDL receptor [29]. In the present study, proteinuria was minimal and hence no change in serum cholesterol level was observed. Vasilis et al. reported that there is no significant change in serum cholesterol level in CKD patients, as these patients were not having any significant degree of proteinuria. Our observation in the present study was in agreement with findings of Vasilis et al. [30] and was characterized by a normal serum cholesterol level due to minimal proteinuria.

The serum LDL-C is not altered in CKD patients both in non dialysis and hemodialysis groups in the present study when compared with control group. Elevated plasma LDL cholesterol is common in nephrotic syndrome but it is not a typical feature of patients with advanced $\mathrm{CKD}$, especially those who are on hemodialysis. A vicious cycle has been suggested in uremia in which the decreased catabolism of IDL and LDL leads to their increased plasma residence time. Using stable isotope techniques it was shown recently that the plasma residence time of LDL and IDL is more than twice as long in hemodialysis patients as in nonuremic individuals. However there is a further modification of the apoB contained in these lipoproteins by oxidation, carbamylation, and glycation [31]. These modifications lead to the reduced recognition and binding of these lipoproteins to LDL receptors and LDL receptor related protein (LRP) in the liver and hence reduction in plasma clearance by this physiologic pathway. This reduced catabolism, which should have resulted in increased serum LDL is however, counterbalanced by the decreased production of LDL, resulting in near-normal plasma levels of LDL. This decreased production of LDL is attributed to the decreased LPL activity [23] which is a major manifestation in CKD as explained earlier, Therefore, our observation that serum LDL cholesterol level does not undergo any change in CKD patients is in agreement with Jain et al. [32].

In the present study, serum HDL-C is significantly decreased in CKD patients both in non dialysis and hemodialysis groups when compared with control. $(\mathrm{p}<0.001$; Table 2$)$ This result is in agreement with Mordasini et al. [33]. The significant decrease of HDL-C in CKD can be attributed to

(i) Decreased levels of apolipoproteins AI and AII; the main protein constituents of HDL [34]

(ii) Diminished activity of LCAT; the enzyme responsible for the esterification of free cholesterol in HDL particles [35].

(iii) Increased activity of Cholesteryl Ester Transfer Protein (CETP) that facilitates the transfer of cholesterol esters from HDL to triglyceride-rich lipoproteins [36].

All these factors combinedly act to reduce the serum concentration of HDL-C.

Serum VLDL-C in the present study is significantly raised in CKD patients both in non dialysis and hemodialysis group when compared with control group $(\mathrm{p}<0.001$; Table 2$)$. This result is in agreement with Bagdade et al. [37]. The factors which explain the increase in serum
VLDL include, (i) the increased activity of CETP which increases transfer of cholesterol ester to VLDL and promotes more VLDL formation [36]. (ii) Increased apo C-III, which is an LPL inhibitor inhibitng the degradation of VLDL [23]. These factors increase the level of serum VLDL-C in CKD patients.

When comparison is made in the present study between the non dialysis and hemodialysis CKD patient groups in respect of lipid parameters (Table 3 ), it is obvious that the serum triglycerides, total cholesterol, HDL-C and VLDL-C levels are significantly decreased in hemodialysis group in comparison to non dialysis group. But there was no appreciable change in serum LDL-C level between both the groups. These changes in hemodialysis patients can be attributed to the removal of lipoproteins by repeated dialysis [38]

Under normal condition, there is a steady state balance between production of free radicals and their destruction by the cellular antioxidative systems. But increased free radical generation, decreased free radical inactivation (due to decreased antioxidant capacity) or combination of both can lead to oxidative stress. In the present study serum MDA value was significantly raised in CKD patients both in non dialysis and hemodialysis groups when compared with control $(\mathrm{p}<0.001$; Table 4). Likewise serum MDA level when compared between both the groups of CKD i.e. non dialysis and hemodialysis groups, it was observed that there was a significant elevation in hemodialysis group $(\mathrm{p}<0.001$; Table 4$)$. The increase in serum MDA level in both groups of CKD patients is a reflection of increased oxidative stress. Chronic kidney disease (CKD) is commonly reported to be associated with oxidative stress. Numerous sources of reactive oxygen species (ROS) have been identified in CKD patients,

(i) Accumulation of uremic toxins, immunologic and metabolic disorders and dyslipidemia [39].

\begin{tabular}{|l|l|l|}
\hline Parameter & $\begin{array}{l}\text { CKD non dialysis } \\
\text { group }(\mathbf{n = 5 0})\end{array}$ & $\begin{array}{l}\text { CKD Hemodialysis group } \\
(\mathbf{n = 4 5})\end{array}$ \\
\hline Triglycerides $(\mathrm{mg} / \mathrm{dl})$ & $209.80 \pm 32.43$ & $195.42 \pm 19.13^{*}$ \\
\hline Total cholesterol $(\mathrm{mg} / \mathrm{dl})$ & $182.46 \pm 22.12$ & $173.71 \pm 22.80^{*}$ \\
\hline HDL-C $(\mathrm{mg} / \mathrm{dl})$ & $35.28 \pm 5.67$ & $29.97 \pm 3.93^{* *}$ \\
\hline LDL-C $(\mathrm{mg} / \mathrm{dl})$ & $105.22 \pm 26.15$ & $104.64 \pm 22.96$ \\
\hline VLDL $(\mathrm{mg} / \mathrm{dl})$ & $41.96 \pm 6.48$ & $39.08 \pm 3.82^{*}$ \\
\hline
\end{tabular}

${ }^{*} \mathrm{p}<0.05$

**P<0.001

The mean serum triglycerides and VLDL are significantly decreased in hemodialysis patients when compared with CKD non dialysis patients $(\mathrm{p}<0.05)$. The mean serum HDL cholesterol is significantly decreased in hemodialysis patients when compared to non dialysis patients $(p<0.001)$. The mean serum total cholesterol is also significantly raised in non dialysis patients when compared to hemodialysis $(p<0.05)$ however these levels were within normal range. LDL cholesterol does not undergo any significant alteration when compared in both the groups

Table 3: Comparative study of lipid profile in CKD in Non dialysis and hemodialysis groups.

\begin{tabular}{|l|l|l|l|}
\hline Parameter & Control $(\mathbf{n = 5 0})$ & $\begin{array}{l}\text { CKD non dialysis } \\
\text { group }(\mathbf{n = 5 0})\end{array}$ & $\begin{array}{l}\text { CKD Hemodialysis } \\
\text { group }(\mathbf{n = 4 5})\end{array}$ \\
\hline MDA $(\mathrm{nmol} / \mathrm{ml})$ & $2.96 \pm 0.51$ & $4.42 \pm 0.58^{* *}$ & $6.16 \pm 0.85^{\star *}$ \\
\hline SOD $(\mathrm{U} / \mathrm{ml})$ & $9.05 \pm 1.47$ & $5.71 \pm 0.84^{* *}$ & $3.61 \pm 0.88^{* *}$ \\
\hline
\end{tabular}

${ }^{* *} p<0.001$

It was observed that the concentrations of serum MDA was significantly higher in CKD in both non dialysis and hemodialysis group when compared to controls. But serum SOD values in CKD registered a significant decline $(p<0.001)$ in both non dialysis and hemodialysis groups when compared to controls

It was also observed that the concentrations of serum MDA in CKD patients was significantly higher $(p<0.001)$ in hemodialysis group when compared to non dialysis patients. But serum SOD values in hemodialysis patients registered a significant decline $(p<0.001)$ when compared to non dialysis patients with CKD

Table 4: Comparative study of serum MDA and SOD in control and CKD Patients. 
(ii) Phagocyte myeloperoxidase-mediated events have also been implicated with the production of oxidized low-density lipoprotein [40].

(iii) Advanced glycation end products and advanced protein oxidation products, which are potent mediators of inflammation, also lead to activation of macrophges [41].

(iv) Treatment of anemia with high levels of iron may also induce oxidative stress [42].

The massive generation of ROS is all the more damaging because CKD patients have a weaker antioxidant system due to a diet low in antioxidant vitamins [43].

In hemodialysis patients the increase is further aggravated after dialysis and this was found to be a statistically significant increase in serum MDA when compared with those patients before hemodialysis $(\mathrm{p}<0.001$; Table 5). Patients on hemodialysis are constantly exposed to oxidative stress. This is mostly attributed to a bioincompatibility of dialysis membrane and diffusion of hydrophilic compounds to the dialysate and influx of endotoxin from the dialysate. These factors lead to activation of macrophages and production of ROS [39]. In addition there is a loss of antioxidants during hemodialysis sessions [44]. All the above factors lead to raised production of free radicals which cause peroxidation of lipids and culminates in further rise in serum MDA level after episodes of dialysis. This is in agreement with the study of Wesen AM [45].

In the present study, the Serum Superoxide Dismutase (SOD) activity significantly decreased in CKD patients both in non dialysis and hemodialysis groups when compared with control ( $p<0.001$; Table 4). Likewise serum SOD level when compared between both the groups of CKD i.e. non dialysis and hemodialysis groups, it was observed that there was a significant decline in the serum SOD level in hemodialysis group ( $\mathrm{p}<0.001$; Table 4 ). When a study was conducted to asses the serum SOD level in hemodialysis group of CKD patients before and after hemodialysis it was observed that in hemodialysis group, the decrease in serum SOD is further aggravated after an episode of dialysis and this decrease was found to be statistically significant when compared with those patients before hemodialysis $(\mathrm{p}<0.05$; Table 5$)$. This study is in agreement with Noleto et al. [46]. The SOD is a metalloenzyme, which is the front line defence against superoxide anions and converts it into hydrogen peroxide. The SOD activity is decreased in CKD patients owing to increased ROS load such as hydrogen peroxide, which is a known suppressant of SOD activity [47]. In hemodialysis three other factors contribute to a further decrease in serum SOD level

(a) The loss of $\mathrm{Zn}^{2+}$ and $\mathrm{Cu}^{2+}$ in the dialysate fluid which act as cofactors of SOD activity [48].

(b) Increased lipid peroxidation especially in hemodialysis patients which results in excess consumption of antioxidant enzyme like SOD [47].

\begin{tabular}{l|l|l|}
\hline Parameter & Before hemodialysis $(\mathbf{n}=\mathbf{4 5})$ & After Hemodialysis $(\mathbf{n}=\mathbf{4 5})$ \\
\hline MDA $(\mathrm{nmol} / \mathrm{ml})$ & $6.16 \pm 0.85$ & $6.83 \pm 0.69^{* *}$ \\
\hline SOD $(\mathrm{U} / \mathrm{ml})$ & $3.61 \pm 0.88$ & $3.11 \pm 0.76^{*}$ \\
\hline${ }^{*} \mathrm{p}<0.05$ & \\
${ }^{* *} \mathrm{p}<0.001$ & \\
After dialysis, concentration of serum MDA in Hemodialysis patients increased \\
further and the concentration of SOD in these patients decreased. These changes \\
were statistically significant ( $p<0.001$ for MDA and $p<0.05$ for SOD) when compared \\
between both the groups before and after dialysis
\end{tabular}

Table 5: Comparative study of serum MDA and SOD in hemodialysis patients before and after dialysis. (c) A significant reduction of SOD due to decreased life span of RBC [49].

Therefore in CKD patients both in non dialysis and hemodialysis group, there is dyslipidemia and oxidative stress.

\section{Conclusion}

In our study dyslipidemia was observed in CKD patients characterized by a statistically significant increase of serum triglycerides and VLDL with a decrease in serum HDL-C in both non dialysis and hemodialysis groups when compared with the controls. However there was no hypercholesterolemia and serum LDL-C was not significantly altered in CKD patients both in non dialysis and hemodialysis groups when compared with controls. The accompanying serum lipid alteration i.e. hypertriglyceridemia, increased serum VLDL and decreased serum HDL in CKD enhance the risk of atherosclerosis and favors higher incidence of cardiovascular complications. Therefore lipid regulation must be instituted to decrease the risk of complications in CKD patients.

In respect of oxidative stress and antioxidant status in CKD patients, it was observed that the serum MDA level was significantly raised and serum SOD level registered a significant decline in both non dialysis and hemodialysis groups compared with control. These factors also contribute to high morbidity and mortality in CKD patients by promoting atherosclerosis and cardiovascular complications. When serum MDA and SOD levels were compared in patients with hemodialysis before and after episodes of dialysis it was also noted that there was a significant increase in serum MDA and decreased SOD after dialysis. Thus after hemodialysis, patients with CKD become more vulnerable to cardiac and cerebrovascular accidents due to enhanced oxidative stress and compromised antioxidant status. Therefore new approaches are to be adapted with reference to dialysis membrane and hemodialysis technique. This modification is to be potentiated with supplementing exogenous antioxidants to counterbalance the ROS which are produced in massive quantity in CKD in the hemodialysis group especially after dialysis. These corrected measures will play a significant role in improving the quality of life in CKD patients especially those who are under hemodialysis.

\section{Acknowledgements}

The authors acknowledge the help and support provided by the Department of Nephrology, Maharajah's institute of medical sciences, Nellimarla, Vizianagaram district. Our heartfelt gratitude and respects to Dr. Pradeep Kumar Behera Professor and H.O.D, Department of Biochemistry, MIMS for his tremendous encouragement and immense support in writing the manuscript. We would also like to thank Institute of Science, GITAM University for providing the necessary facilities to carry out this work.

\section{References}

1. Eknoyan G, Lameire N, Barsoum R, Eckardt KU, Levin A, et al. (2004) The burden of kidney disease: improving global outcomes. Kidney Int 66: 13101314.

2. Levey AS, Eckardt KU, Tsukamoto Y, Levin A, Coresh J, et al. (2005) Definition and classification of chronic kidney disease: a position statement from Kidney Disease: Improving Global Outcomes (KDIGO). Kidney Int 67: 2089-2100.

3. Attman PO, Samuelsson O, Alaupovic P (1993) Lipoprotein metabolism and renal failure. Am J Kidney Dis 21: 573-592.

4. Deighan CJ, Caslake MJ, McConnell M, Boulton-Jones JM, Packard CJ (2000) Atherogenic lipoprotein phenotype in end-stage renal failure: origin and extent of small dense low-density lipoprotein formation. Am J Kidney Dis 35: 852-862.

5. Sandau KB, Brüne B (2000) Up-regulation of Bcl-2 by redox signals in glomerular mesangial cells. Cell Death Differ 7: 118-125. 
Citation: Raju DSSK, Lalitha DL, Kiranmayi P (2013) A Study of Lipid Profile and Lipid Peroxidation in Chronic Kidney Disease with Special Reference to Hemodialysis. J Clinic Res Bioeth 4: 143. doi:10.4172/2155-9627.1000143

Page 5 of 5

6. Zou AP Cowley AW Jr (2003) Reactive oxygen species and molecular regulation of renal oxygenation. Acta Physiol Scand 179: 233-241.

7. Bedard K, Krause KH (2007) The NOX family of ROS-generating NADPH oxidases: physiology and pathophysiology. Physiol Rev 87: 245-313.

8. Massy ZA, Nguyen-Khoa T (2002) Oxidative stress and chronic renal failure: markers and management. J Nephrol 15: 336-341.

9. Tiffany TO, Jansen JM, Burtis CA, Overton JB, Scott CD (1972) Enzymatic kinetic rate and end-point analyses of substrate, by use of a GeMSAEC fast analyzer. Clin Chem 18: 829-840.

10. Bowers LD (1980) Kinetic serum creatinine assays I. The role of various factors in determining specificity. Clin Chem 26: 551-554.

11. Allain CC, Poon LS, Chan CS, Richmond W, Fu PC (1974) Enzymatic determination of total serum cholesterol. Clin Chem 20: 470-475.

12. Burstein M, Scholnick HR, Morfin R (1970) Rapid method for the isolation of lipoproteins from human serum by precipitation with polyanions. J Lipid Res 11: $583-595$.

13. McGowan MW, Artiss JD, Strandbergh DR, Zak B (1983) A peroxidase-coupled method for the colorimetric determination of serum triglycerides. Clin Chem 29: 538-542.

14. Friedewald WT, Levy RI, Fredrickson DS (1972) Estimation of the concentration of low-density lipoprotein cholesterol in plasma, without use of the preparative ultracentrifuge. Clin Chem 18: 499-502.

15. Kakkar P, Das B, Viswanathan PN (1984) A modified spectrophotometric assay of superoxide dismutase. Indian J Biochem Biophys 21: 130-132.

16. Satoh K (1978) Serum lipid peroxide in cerebrovascular disorders determined by a new colorimetric method. Clin Chim Acta 90: 37-43.

17. Raju DSSK, Lalitha DL, Kiranmayi P (2012) Observation of estimated GFR in the assessment of chronic kidney disease: application and practice. Asian $\mathrm{J}$ Pharm Clin Res. 5(4): 201-206.

18. Saland J M, Ginsberg H N (2007) Lipoprotein metabolism in chronic renal insufficiency. Pediatr Nephrol. 22:1095-1112.

19. Kwan BC, Kronenberg F, Beddhu S, Cheung AK (2007) Lipoprotein metabolism and lipid management in chronic kidney disease. J Am Soc Nephrol 18: 1246 1261.

20. Basha SA, Singh DS, Kotiyal JP, Bisht DB (1979) Study of lipid profile and alimentary lipemia in chronic renal failure. J Assoc Physicians India 27: 10791083.

21. Prinsen BH, de Sain-van der Velden MG, de Koning EJ, Koomans HA, Berge $\mathrm{R}$, et al. (2003) Hypertriglyceridemia in patients with chronic renal failure: possible mechanisms. Kidney Int Suppl : S121-124.

22. Vaziri ND, Liang K (1996) Down-regulation of tissue lipoprotein lipase expression in experimental chronic renal failure. Kidney Int 50: 1928-1935.

23. Moberly JB, Attman PO, Samuelsson O, Johansson AC, Knight-Gibson C et al. (1999) Apolipoprotein C-III, hypertriglyceridemia and triglyceride-rich lipoproteins in uremia. Miner Electrolyte Metab 25: 258-262.

24. Huttunen JK, Pasternack A, Vanttinen T, Ehnholm C, Nikkila EA (1978) Lipoprotein metabolism in patients with chronic uremia. Effect of hemodialysis on serum lipoproteins and postheparin plasma triglyceride lipases. Acta Med Scand. 204: 211-218.

25. Cheung AK, Parker CJ, Ren K, Iverius PH (1996) Increased lipase inhibition in uremia: identification of pre-beta-HDL as a major inhibitor in normal and uremic plasma. Kidney Int 49: 1360-1371.

26. Vaziri ND, Wang XQ, Liang K (1997) Secondary hyperparathyroidism downregulates lipoprotein lipase expression in chronic renal failure. Am J Physiol 273: F925-930.

27. Appel G (1991) Lipid abnormalities in renal disease. Kidney Int 39: 169-183.

28. Tsumura M, Kinouchi T, Ono S, Nakajima T, Komoda T (2001) Serum lipid metabolism abnormalities and change in lipoprotein contents in patients with advanced-stage renal disease. Clin Chim Acta 314: 27-37.

29. Liang K, Vaziri ND (1997) Gene expression of LDL receptor, HMG-CoA reductase, and cholesterol-7 alpha-hydroxylase in chronic renal failure. Nephrol Dial Transplant 12: 1381-1386.

30. Tsimihodimos V, Mitrogianni Z, Elisaf M (2011) Dyslipidemia associated with chronic kidney disease. Open Cardiovasc Med J 5: 41-48.

31. Ikewaki K, Schaefer JR, Frischmann ME, Okubo K, Hosoya T, et al. (2005) Delayed in vivo catabolism of intermediate-density lipoprotein and lowdensity lipoprotein in hemodialysis patients as potential cause of premature atherosclerosis. Arterioscler Thromb Vasc Biol 25: 2615-2622.

32. Jain PK, Arora RC, Agarwal N, Garg RK, Arora S, et al. (1991) Dietary cholesterol induced changes in lipid profile in patients with nephrotic syndrome and chronic renal failure. J Assoc Physicians India 39: 751-753.

33. Mordasini R, Frey F, Flury W, Klose G, Greten H (1977) Selective deficiency of hepatic triglyceride lipase in uremic patients. N Engl J Med 297: 1362-1366.

34. Vaziri ND, Deng G, Liang K (1999) Hepatic HDL receptor, SR-B1 and Apo A-I expression in chronic renal failure. Nephrol Dial Transplant 14: 1462-1466.

35. Guarnieri GF, Moracchiello M, Campanacci L, Ursini F, Ferri L, et al. (1978) Lecithin-cholesterol acyltransferase (LCAT) activity in chronic uremia. Kidney Int Suppl : S26-30.

36. Kimura H, Miyazaki R, Imura T, Masunaga S, Suzuki S, et al. (2003) Hepatic lipase mutation may reduce vascular disease prevalence in hemodialysis patients with high CETP levels. Kidney Int 64: 1829-1837.

37. Bagdade J, Casaretto A, Albers J (1976) Effects of chronic uremia, hemodialysis, and renal transplantation on plasma lipids and lipoproteins in man. J Lab Clin Med 87: 38-48.

38. Shah B, Nair S, Sirsat RA, Ashavaid TF, Nair KG (1994) Dyslipidemia in patients with chronic renal failure and in renal transplant patients. J Postgrad Med 40: 57-60

39. Locatelli F, Canaud B, Eckardt KU, Stenvinkel P, Wanner C, et al. (2003) Oxidative stress in end-stage renal disease: an emerging threat to patien outcome. Nephrol Dial Transplant 18: 1272-1280.

40. Nguyen-Khoa T, Massy ZA, Witko-Sarsat V, Canteloup S, Kebede M, et al. (1999) Oxidized low-density lipoprotein induces macrophage respiratory burst via its protein moiety: A novel pathway in atherogenesis? Biochem Biophys Res Commun 263: 804-809.

41. Witko-Sarsat V, Friedlander M, Nguyen Khoa T, Capeillère-Blandin C, Nguyen AT, et al. (1998) Advanced oxidation protein products as novel mediators of inflammation and monocyte activation in chronic renal failure. J Immunol 161 2524-2532.

42. Drüeke T, Witko-Sarsat V, Massy Z, Descamps-Latscha B, Guerin AP, et al. (2002) Iron therapy, advanced oxidation protein products, and carotid artery intima-media thickness in end-stage renal disease. Circulation 106: 2212-2217.

43. Bonnefont-Rousselot D, Lehmann E, Jaudon MC, Delattre J, Perrone B, et al. (2000) Blood oxidative stress and lipoprotein oxidizability in haemodialysis patients: effect of the use of a vitamin E-coated dialysis membrane. Nephro Dial Transplant 15: 2020-2028.

44. Nguyen-Khoa T, Massy ZA, Witko-Sarsat $V$, Thévenin $M$, Touam $M$, et al. (1999) Critical evaluation of plasma and LDL oxidant-trapping potential in hemodialysis patients. Kidney Int 56: 747-753.

45. Wesen AM (2011) Determination of Resistin and Several Antioxidant in sera of patients with chronic renal failure. Australian Journal of Basic and Applied Sciences. 5(8): 196-203.

46. Noleto Magalhaes RC, Guedes Borges de Araujo C, Batista de sousa Lima V, Machado Moita Neto J, Do Nascimento Nogueira N et al. (2011) Nutritional status of zinc and activity superoxide dismutase in chronic renal patients undergoing hemodialysis. Nutr Hosp. 26(6): 1456-1461.

47. Toborek M, Wasik T, Drózdz M, Klin M, Magner-Wróbel K, et al. (1992) Effect of hemodialysis on lipid peroxidation and antioxidant system in patients with chronic renal failure. Metabolism 41: 1229-1232.

48. Kiziltas H, Ekin S, Erkoc R (2008) Trace element status of chronic renal patients undergoing hemodialysis. Biol Trace Elem Res 124: 103-109.

49. Shainkin-Kestenbaum R, Caruso C, Berlyne GM (1990) Reduced superoxide dismutase activity in erythrocytes of dialysis patients: a possible factor in the etiology of uremic anemia. Nephron 55: 251-253. 